\title{
Analisis Spiritualisasi Pendidikan Islam dalam Hubungan Bermasyarakat di Desa Hajoran Kabupaten Labuhanbatu Selatan
}

\author{
Tuti Anggraini ${ }^{1 *}$, Ade Sakila² ${ }^{2}$ Aida Sulam Tambak ${ }^{3}$, Bunga Syafira \\ Dalimunthe ${ }^{4}$, Dinda Rahayu ${ }^{5}$, Dini Syara Sagala ${ }^{6}$, Hasnia Ananda Harahap ${ }^{7}$, \\ Nanda Sholehah ${ }^{8}$ \\ ${ }^{1}$ Universitas Islam Negeri Sumatera Utara Medan, Indonesia \\ ${ }^{2}$ Universitas Islam Negeri Sumatera Utara Medan, Indonesia \\ ${ }^{3}$ Universitas Islam Negeri Sumatera Utara Medan, Indonesia \\ ${ }^{4}$ Universitas Islam Negeri Sumatera Utara Medan, Indonesia \\ ${ }^{5}$ Universitas Islam Negeri Sumatera Utara Medan, Indonesia \\ ${ }^{6}$ Universitas Islam Negeri Sumatera Utara Medan, Indonesia \\ ${ }^{7}$ Universitas Islam Negeri Sumatera Utara Medan, Indonesia \\ ${ }^{8}$ Universitas Islam Negeri Sumatera Utara Medan, Indonesia \\ * Corresponding Author. E-mail: ${ }^{1}$ nandasholiha13september200@gmail.com
}

Receive: $10 / 08 / 2021$

Accepted: $30 / 08 / 2021$

Published: 01/10/2021

\begin{abstract}
Abstrak
Manusia adalah makhluk yang sadar, yang berarti bahwa ia sadar terhadap semua alasan tingkah lakunya, sadar inferioritasnya, mampu membimbing tingkah lakunya, dan menyadari sepenuhnya arti dari segala perbuatan untuk kemudian dapat mengaktualisasikan dirinya. Spiritualitas dan agama memiliki hubungan dengan aspek kognitif, emosional, perilaku, interpersonal dan psikologis yang membentuk sebagai pendekatan holistik untuk memahami manusia. Penelitian ini bertujuan untuk melihat bagaimana perumusan definisi agama dan spiritual (keyakinan) dalam hubungan bermasyarakat yang komprehensif dan jelas dapat membantu dalam menentukan makna dan pengaruh agama dan keyakinan guna membantu masyarakat menghadapi dan mengatasi masalah mereka. Penelitian ini menggunakan metode kualitatif dengan pendekatan studi kasus. Pengumpulan data dilakukan dengan cara wawancara dan observasi. Responden penelitian ini meliputi warga desa dengan usia lanjut yang berada di Desa Hajoran Tongah dan Hajoran Simaninggir Kabupaten Labuhanbatu Selatan. Berdasarkan analisis data diketahui hasil penelitian bahwa kegiatan dan hubungan keagamaan di Desa Hajoran sangat baik, di mana masyarakat yang begitu antusias mengikuti kegiatan-kegiatan keagamaan, seperti suluk yang diadakan di Desa Hajoran yang mana menambah optimis tasawuf dan tarekatnya akan muncul menjadi semangat hidup di zaman sekarang ini.
\end{abstract}

Kata Kunci: Spiritualisasi, Keagamaan, Masyarakat 
Jurnal Edumaspul, 5 (2), Year 2021- 33

(Tuti Anggraini, Ade Sakila, Aida Sulam Tambak, Bunga Syafira Dalimunthe, Dinda Rahayu, Dini Syara Sagala, Hasnia Ananda Harahap, Nanda Sholehah)

\title{
Analysis of Spiritualization of Islamic Education in Community Relations in Hajoran Village, South Labuhanbatu Regency
}

\begin{abstract}
Man is a conscious being, which means that he is aware of all the reasons for his behavior, is aware of his inferiority, is able to guide his behavior, and is fully aware of the meaning of all actions so that he can then actualize himself. Spirituality and religion have a relationship with cognitive, emotional, behavioral, interpersonal and psychological aspects that form a holistic approach to understanding Humans. This study aims to see how the formulation of a comprehensive and clear definition of religion and spiritual (belief) in social relations can assist in determining the meaning and influence of religion and belief in order to help people face and overcome their problems. This study uses a qualitative method with a case study approach. Data was collected by means of interviews and observations. The respondents of this study included elderly villagers in the villages of Hajoran Tongah and Hajoran Simaninggir, South Labuhanbatu Regency. Based on data analysis, it is known that the results of the study show that religious activities and relations in Hajoran Village are very good, where people are so enthusiastic about participating in religious activities, such as Suluk held in Hajoran Village which adds to the optimism of Sufism and his determination will emerge into the spirit of life in this day and age.
\end{abstract}

Keywords: Spiritualization, Religion, Society.

\section{Pendahuluan}

Pada zaman sekarang Agama dan kepercayaan memberikan suatu acuan dasar dan kerangka pedoman yang mengarahkan individu bersikap religius serta memunculkan rasa tanggung jawab etis di tengah-tengah dunia yang penuh dengan dualisme dan relativisme. Ketika keseluruh responden diberikan pertanyaan yang erat hubungannya dengan sesama yang membutuhkan mereka menjawab akan memberikan bantuan sekalipun berada dalam kondisi berkekurangan. Memberikan bantuan tidak hanya seputaran materi saja, dengan memberikan perhatian saja itulah wujud dari tanggung jawab etis berkaitan dengan sikap religiusnya.

Spiritualitas dan agama memiliki hubungan dengan aspek kognitif, emosional, perilaku, interpersonal dan psikologis yang membentuk sebagai pendekatan holistik untuk memahami individu. Banyak penelitian telah membahas agama dan spiritualitas yang mempengaruhi dalam kehidupan manusia.

Agama yang dilepaskan dari religiusitas akan menjadi kering karena terputus dari mata airnya. Agama menjadi mati karena kehilangan jiwa dan semangatnya. Kesadaran beragama harus ditumbuhkan melalui penghayatan yang tinggi terhadap nilai transendental, sehingga penghayatan tersebut mampu menumbuhkan kualitas-kualitas moral dan keluhuran budi manusia. Oleh karena itu, agama harus dikembalikan pada religiusitas melalui usahausaha rohani manusia dan melalui wahyu yang dialami dalam kehidupan nyata melalui pengalaman religius.

Banyak penelitian telah dilakukan mengenai peran spiritualitas terhadap aspekaspek kehidupan manusia dan hasilnya telah bervariasi. Misalnya hasil penelitian Pargament \& Park (1997: 43-53) yang menunjukkan bahwa individu yang lebih religius atau spiritual, dan menggunakan spiritualitasnya untuk mengatasi hidup, mengalami banyak manfaat untuk 
kesehatan dan kesejahteraan. Penelitian Koenig \& Larson (2001: 67-78) serta hasil penelitian Gartner et.al (1991: 6-25) yang telah menemukan bahwa religiusitas berkorelasi positif dengan penyesuaian, beberapa penelitian juga telah menemukan bahwa religiusitas berkorelasi negatif dengan penyesuaian, misalnya hasil penelitian Schaefer (1997: 633). Sementara hasil penelitian Lewis, et.al (1997: 119) justru tidak menemukan hubungan yang signifikan sama sekali.

Berbagai definisi dari dua konsep telah diusulkan oleh para ahli yang berbeda dengan berbagai pandangan mulai dari polarisasi dari dua konsep tersebut, keterkaitan antara spiritualitas dan agama, sampai ada pula beberapa ulama yang menyarankan salah satunya menjadi subdomain dari yang lain, sementara ulama lain menyarankan berlawanan. Reich (1996:149) menyebutkan empat cara yang bisa dilakukan untuk menggambarkan hubungan antara religiusitas dan spiritualitas, yaitu: bahwa keduanya adalah domain yang terpisah, bahwa keduanya adalah domain yang berbeda tetapi tumpang tindih, bahwa keduanya adalah sama, dan bahwa salah satu adalah subdomain bagi yang lain.

Kelly (1995: 227) mengemukakan bahwa spiritualitas merupakan pengalaman subjektif seseorang dari transendental sifat alam semesta sementara agama dianggap ekspresi institusional dalam menampilkan spiritualitas Spiritualitas adalah pengalaman universal, kurang dibatasi oleh doktrin terkait dengan agama tertentu.

Mengingat definisi spiritualitas dan agama yang disebutkan di atas bervariasi, maka kiranya bijaksana untuk mempertimbangkan pendapat. Singleton et al (2004: 250) dalam menawarkan definisi spiritualitas dengan kesadaran tujuan hidup berdasarkan rujukan transenden. Bahwa definisi spiritual tidak leksikal. Ini berarti bahwa Singleton tidak membuat klaim bahwa definisi spiritualitasnya adalah ringkasan dari bagaimana orang lain menggunakan konsep tersebut. Singleton et.al (2004: 250) juga tidak bertujuan untuk membangun definisi secara defnitif konsep tersebut. Sebaliknya, Singleton menawarkan definisi stipulatif berupa konsep kompleks dalam hal apa artinya spiritualitas dalam suatu konteks atau pembahasan tertentu. Berdasarkan penjelasan di atas dapat ditegaskan bahwa spiritualitas lebih luas daripada agama namun saling terkait dengan agama (Benson, et.al., 2003: 208). Pada tulisan ini, kata spiritualitas dan agama akan digunakan secara bersamaan dan terkadang secara bergantian dalam hubungan bermasyarakat

Oleh karena itu, perumusan definisi agama dan spiritual (keyakinan) dalam hubungan bermasyarakat yang komprehensif dan jelas dapat membantu dalam menentukan makna dan pengaruh agama dan keyakinan guna membantu masyarakat menghadapi dan mengatasi masalah mereka. Demikian juga, definisi sprituaitas agama dalam hubungan masyarakat yang jelas akan membantu.

\section{Metode}

Penelitian ini merupakan sebuah penelitian kualitatif dengan pendekatan studi kasus. Studi kasus (case study) adalah sebuah model yang memfokuskan eksplorasi "sistem terbatas" (bounded system) atas satu kasus khusus ataupun pada sebagian kasus secara terperinci dengan penggalian data secara mendalam. Beragam sumber informasi yang kaya akan konteks dilakukan untuk penggalian data (Creswell, 2015). Selain itu, studi kasus juga digunakan ketika suatu peristiwa atau kasus terjadi secara alamiah dan peneliti tidak memiliki kemampuan untuk mempengaruhi peristiwa tersebut. Pendekatan studi kasus dipilih untuk memperoleh informasi yang mendalam terkait suatu peristiwa dalam sebuah desa. 
Responden penelitian ini meliputi warga desa dengan usia lanjut. Penelitian ini menggunakan wawancara dan observasi dalam mengumpulkan data. Pengambilan data dilakukan di Desa Hajoran Tongah dan Hajoran Simaninggir yang berada di Kabupaten Labuhanbatu Selatan.

Analisis data dilakukan dengan mengkategorikan data-data yang menggambarkan proses atau tema tertentu menjadi sebuah model yang dipahami. Analisis data dilakukan melalui tiga tahap pemberian kode (coding) yaitu open coding, axial coding dan selective coding. Data-data yang diperoleh kemudian harus melalui sebuah proses penilaian terhadap data yang diperoleh agar data tersebut bisa dipercaya. Peneliti menggunakan beberapa langkah untuk menjaga kredebilitas data yang diperoleh antara lain dengan membuat catatan dan mendokumentasikan semua data yang diperoleh serinci mungkin serta melakukan triangulasi data yakni menggunakan beragam sumber data untuk memperoleh jawaban penelitian.

\section{Hasil dan Pembahasan}

Peneliti ketika menjalani kehidupannya dengan pemaknaan spiritualisasi yang peneliti miliki, hal ini diperoleh ketika peneliti mampu menggabungkan antara konsep ibadah secara syariat islam dan tarekat/suluk. Dengan berpedoman "Ahlussunnah wal jama'ah" artinya yang mengikuti dan berpegang teguh dengan sunnah Nabi dan sunnah Khulafarrasyidin setelahnya, hal ini menjadikan kehidupan peneliti lebih seimbang. Peneliti juga merasakan kehadiran Tuhan dalam kehidupannya. Terlebih ketika sedang beribadah, peneliti mampu merasakan kenikmatan yang luar biasa. Pencapaian dan pengalaman spiritualisasi oleh peneliti menjadikannya mampu memahami dalam dirinya tentang kehidupan yang hakiki.
Dalam aspek makna dan tujuan dalam hidup dapat diketahui manusia selalu mengabdi kepada Tuhan Yang Maha Esa, orang tua, para leluhur dan guru. Dan untuk saling tolong menolong dan mengasihi sesama makhluk. Hal ini dapat ditunjukkan dengan bertirakat dan memohon petunjuk kepada guru untuk membimbing manusia memaknai kehidupan dan mencari tujuan hidup dengan belajar dan terus belajar.

Aspek misi dalam hidup manusia, bahwa manusia harus mengetahui jati diri masing-masing untuk sampai pada tingkatan ma'rifat billah atau mengenal Tuhan dalam arti yang sebenarnya. Didaamnya guru spiritual juga melakukan misi hidupnya untuk menyebarkan kebaikan dengan membina akhlak para muridnya dari hati ke hati, dengan tujuan menegakkan kebenaran di sisi Tuhan. Hal ini dilakukan karena yang terpenting di dalam hidup adalah kebersamaan dan kemaslahatan umat.

Aspek kesucian dalam hidup peneliti dengan memahami bahwa manusia tidak ada yang suci, karena kesucian hanya milik Tuhan semata, namun manusia tetap harus mencari kebenaran dan kesucian dalam hidup lewat bimbingan guru yang mampu memberikan penerangan dalam jiwa, serta menjalani kehidupan dan semua hal yang ada didalamnya dengan tidak mengejar kemewahan dunia yang akan dapat menjadikan diri dari jiwa yang bersih.

Aspek nilai-nilai kebendaan, diketahui bahwa harta hendak hanyalah sebagai lantaran untuk hidup dan subjek mampu menerima kehidupan yang secara ekonomidapat dikatakan sederhana. Peneliti memiliki pandangan bahwa selama seseorang mau berusaha dan mendekatkan diri dengan Tuhan, Tuhan akan mencukupi kebutuhan hariannya. Peneliti juga menyatakan bahwa kedudukan dan harta benda sudah merupakan pemberian Tuhan. peneliti dapat menyadari dan bersyukur kebahagiaan tertinggi dalam kehidupan berasal 
dari nilai-nilai spiritualisasi, dan harta bukanlah kepuasan dan kebahagiaan tertinggi.

Aspek altruism atau menilai pentingnya interaksi dengan orang lain dapat diketahui dari peneliti bahwa peneliti menilai interaksi sosial di masyarakat sangat penting, dan peneliti tetap melakukan interaksi meskipun orang lain tidak sepaham.

Pada aspek idealisme atau menghargai potensi-potensi positif pada orang lain diterapkan pada kehidupan, dengan menghargai orang lain dan memercayai akan kebaikan dan potensi positif lainnya. Dengan menghormati dan meyakini bahwa yang diterima merupakan ujian dari Tuhan dalam berjuang menegakkan agama.

Kesadaran akan kemampuan tinggi untuk berempati memaknai bahwa dalam setiap pencarian pasti butuh pengorbanan, dan seseorang harus mampu menahan gejolak ego dan emosi, serta mengambil nilai atau hikmah dari setiap permasalahan agar tertanam menjadi jiwa yang tenang. Manfaat spiritualisasi adalah membangun jiwa yang tenang, dimana sifat dedikasi itu ada ketika semua orang tidak membeda-bedakan ras.

Dari uraian diatas, hasil ini dapat menunjukkan bahwa spiritualisme dalam islam yang diambil dari penelitian yang ada yakni desa hajoran terdapat persulukan yang bernama Suluk Nurul Munir. Dulunya persulukan ini, nama pemiliknya adalah Abdullah Munir Dasopang. Namun, setelah itu pada tahun 1976 beliau meninggal dunia. Pada tahun 2009-2013, bapak Syah Rambe beliau dipanggil untuk memimpin persulukan. Dilanjutkan dengan sang anak yaitu tuan () yang memimpin dari tahun 2013 hingga saat ini. Beliau juga disebut sebagai mursit (pemimpin persulukan). Tujuan persulukan adalah berdzikir selama 10 hari 10 malam. Suluk berarti memperbaiki akhlak, mensucikan amal, dan menjernihkan pengetahuan. Suluk merupakan aktivitas rutin dan memakmurkan lahir batin. Segenap kesiukan hamba hanya ditujukan kepada sang Rabb. Suluk merupakan bagian dari ajaran tasawuf yaitu suatu ajaran yang mendorong pengikutnya untuk mencari kesempurnaan hidup dan dekat dengan Tuhan melalui berbagai cara. Sebelum mengikuti suluk, biasanya masyarakat/orang yang sudah kuat ibadahnya akan melakukan tahapan seperti mengikuti tarekat sebagai langkah awal untuk menguatkan jiwa yang menyatu dan mendekatkan diri dengan Tuhan. Bedanya, untuk pelaksanaan tarekat itu dilakukan sekali dalam setiap minggunya sedangkan suluk dilakukan bermacam mulai dari 10 hari 10 malam hingga sebulan. Dalam kegiatan suluk sendiri biasanya salik (orang yang suluk) tidak memakan lauk yang berdarah, karena itu dapat menambah nasu sedangkan suluk sendiri tujuannya menjauhkan diri dari hawa nafsu yang tinggi. Suluk dilakukan dengan merendahkan nafsu. Orang yang besuluk melakukan kegiatan berkunjung ke maqam dan berdoa. Persulukan ini dilakukan setiap 3 bulan sekali. Orang yang mengikuti suluk dimulai dari usia +25 tahun.

\section{Simpulan}

Spiritualisme di dalam agama adalah kepercayaan, atau praktek-praktek yang berdasarkan kepercayaan bahwa jiwa-jiwa yang berangkat (saat meninggal) tetap bisa mengadakan hubungan dengan jasad. Hubungan ini umumnya dilaksanakan melalui seorang medium yang masih hidup. Ada keterlibatan emosional yang kuat, baik pada penolakan maupun penerimaan terhadap spiritualisme ini yang membuat sulitnya suatu uraian imparsial dipakai untuk membuktikannya.

Ketika menjalani kehidupannya dengan pemaknaan spiritualisasi yang dimiliki seseorang, hal ini diperoleh ketika mampu menggabungkan antara konsep ibadah secara syariat islam dan tarekat/suluk. Dalam aspek makna dan tujuan dalam hidup dapat diketahui 
manusia selalu mengabdi kepada Tuhan Yang Maha Esa, orang tua, para leluhur dan guru. Dan untuk saling tolong menolong dan mengasihi sesama makhluk. Hal ini dapat ditunjukkan dengan bertirakat dan memohon petunjuk kepada guru untuk membimbing manusia memaknai kehidupan dan mencari tujuan hidup dengan belajar dan terus belajar.

Berdasarkan analisis data diketahui hasil penelitian bahwa kegiatan dan hubungan keagamaan di Desa Hajoran sangat baik, dimana masyarakat yang begitu antusias mengikuti kegiatan-kegiatan keagamaan, seperti suluk yang diadakan didesa Hajoran yang mana menambah optimis tasawuf dan tarekatnya akan muncul menjadi semangat hidup di zaman sekarang ini.

\section{Daftar Pustaka}

[1] Agustiawan, M. Nasir. (2017). Spiritualisme dalam Islam. Tangerang: Sekolah Tinggi Ilmu Hukum Painan.

[2] Creswell, J. W. (2015). Penelitian Kualitatif \& Desain Riset. Yogyakarta: Pustaka Pelajar.

[3] Gartner, J., et.al. (1991). Religious Commitment and Mental Health: A Review of The Empirical Literature. Journal of Psychology and Theology, 19(1), 6-25.

[4] Hawari, Dadang. (2002). Dimensi Religi dalam Praktik Psikiatri dan Psikologi. Jakarta: Fakultas Kedokteran Universitas Indonesia.
[5] Kelly, E.W.Jr. (1995). Spirituality and Religion in Counselor Education: A National Survey. Journal Counselor Education and Supervision, 33(1), 2227237.

[6] Koenig, H. G. \& Larrson, D. B. (2001). Religion and Mental Health: Evidence for An Association. Journal International Review of Psychiatry, 13(1), 67-78.

[7] Lewis, C. A., et.al. (1997). Religiosity and Happiness: No Evidence for An Association Among Undergraduates. Journal Personality and Individual Differences, 22(1), 119-121.

[8] Pargament, K. I. \& Park, C. L. (1997). In Times of Stress: The Religion-Coping Connection. In B. Spilka \& D.N. Mclntosh (Eds.), The Psychology of Religion: Theoretical Approaches. Boulder, CO: Westview Press.

[9] Ruslan, H. M. (2008). Menyingkap Rahasia Spiritualitas Ibnu Arabi. Cet. I. Makassar: Al-Zikra.

[10] Schaefer, W. E. (1997). Religiosity, Spirituality, and Personal Distress Among College Students. Journal of College Student Development, 38(1), 633-644.

[11] Singleton, A., et.al. (2004). Spirituality in Adolescence and Young Adulthood: $A$ Method for A Qualitative Study. International Journal of Children's Spirituality, 9(3), 247-262. 